\title{
US urged to explore accelerator options
}

[WASHINGTON] The United States is not ready to build any more new particle accelerators, two separate panels of scientists have told the government. But it should press on with the conceptual design of a new linear accelerator, as well as researching options for other machines that might be built early in the next century.

While these ideas are being developed, the panels say, the top priorities in highenergy physics should be US participation in the Large Hadron Collider (LHC) project at CERN, the European Laboratory for Particle Physics in Geneva, Switzerland, and securing increased funding for particle physicists at universities.

The High Energy Physics Advisory Panel (HEPAP), which advises the Department of Energy on its $\$ 700$ million-a-year highenergy physics programme, last week endorsed one of the reports, prepared by a panel chaired by Frederick Gilman of Carnegie-Mellon University in Pittsburgh.

The panel says that the Stanford Linear
Accelerator Center in California should create a conceptual design for an electron-positron linear collider "in close collaboration". But it says emphatically: "This is not a recommendation to proceed with construction."

At the same time, a National Research Council panel chaired by Bruce Winstein of the University of Chicago issued a substantially similar set of recommendations. Like HEPAP, it calls for the development of a conceptual design for a linear accelerator with an collision energy of up to $1.5 \mathrm{TeV}$.

Recommending that research should be "vigorously pursued" into technologies for future muon and very large hadron colliders, the Winstein panel says this effort "should focus on a reduction of cost through the use of advanced technologies". The report does not express a view on which of these concepts is most promising.

Energy department officials welcome the modest consensus struck by the reports.
"Everybody agrees we need to bring the design forward before ap proving construction" of a new linear collider, says Bob Diebold, HEPAP's executive secretary.

Winstein says his panel's 160-page report was supposed to make the case for particle physics to Congress and a wider public.

"We feel it is our obligation to speak more clearly and more frequently to the public," Winstein says.

US plans to participate in the LHC p roject have already received some unwanted attention from the Congress. Money for the LHC was included in a list of "questionable funding increases" issued by Bob Livingston (Republican, Louisiana), the chair of the Appropriations Committee in the House of Representatives.

Officials had expected trouble for the project in Congress, but they believe that Livingston's prime motive is to use the international LHC agreement to obtain leverage with the administration, not to end US participation in the project.

Colin Macilwain

\section{UK nuclear physicists set to lose their privileged funding status}

[LONDON] The United Kingdom's dwindling band of nuclear physicists are to lose their protected status within the science budget under proposals set out yesterday ( 25 February) by the Engineering and Physical Sciences Research Council (EPSRC).

For the past five years, nuclear physicists have been allocated about $\mathfrak{E} 5$ million (US $\$ 8$ million) of research funding each year, distributed by the nuclear physics panel of the EPSRC. The budget was guaranteed partly as a quid pro quo for the government's decision to make nuclear physics the responsibility of the EPSRC instead of the Particle Physics and Astronomy Research Council when the United Kingdom's science funding councils were reorganized in 1993.

From next year, however, this small community of 60 researchers will have to compete for funds alongside other physics disciplines, with the applications assessed by a general panel of EPSRC physicists. The research council believes it is time that nuclear physics was judged on its merits. A spokesman adds that the changes will allow the discipline to "grow or recede according to the quality of proposals".

Nuclear physicists have mixed reactions to the proposed change. Few are concerned about the quality of research proposals and thus their likely success in broader competition - describing the UK's nuclear physics as "among the best in the world". But some fear that the change in funding arrangements could divide a close-knit

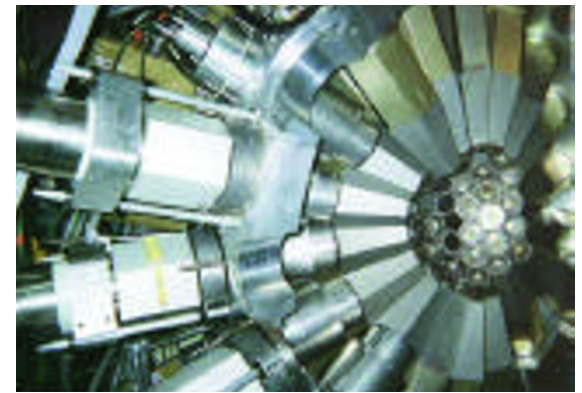

Unstable future? Nuclear physics research will have to compete alongside other disciplines.

community of researchers, and deprive the field of its long-term focus.

John Durell, for example, head of the nuclear structure group at the University of Manchester, says that ring-fenced funds allow different research groups to meet and decide which areas to focus on before applying for funds. They also give research teams time to plan their research, and make advance bookings of international nuclear structure facilities.

Indeed, the Institute of Physics is concerned that a general EPSRC panel of physics researchers may not be the best way of assessing nuclear physics research proposals. "The institute has received comments from the community that existing panels do not have the knowledge to deal with the current range of proposals," says a spokesman. "The inclusion of nuclear physics in the panel will exacerbate the problem."
Despite the current enthusiasm for particle physics, nuclear physics - which deals with the interactions between protons, neutrons and electrons - still has much to offer, say researchers. On the theory side, for example, fundamental questions about nuclear structure remain, such as why atoms change shape when neutrons are added or taken away.

Another area, nuclear isomers, is concerned with excited nuclear states that live for long periods. "If we can release this energy in a controlled way, we may have a possible energy store," says Phil Walker, professor of physics at the University of Surrey, and leader of the university's nuclear physics group.

The relatively small size of the nuclear physics community partly reflects the discipline's status as a 'poor relation' to particle physics. But it is also due to the United Kingdom's lack of a low-energy particle accelerator - needed to probe the structure of the nucleus - since the Nuclear Structure Facility at Daresbury in Cheshire closed in 1993 (see Nature 362, 278; 1993).

The head of one nuclear physics group says that the lack of an indigenous facility remains more of a threat to UK nuclear physics than any change in funding arrangements. "We need to find a way to build a new British facility," he says.

"It's embarrassing in that we are sponging facilities overseas, but not offering anything in return. It is as if we were a Third World country."

Ehsan Masood 